\title{
THE IMPORTANCE OF FREE ZONES ON TURKEY'S EXPORT: PRELIMINARY RESEARCH WITHIN THE FRAMEWORK OF PURPOSE-PERFORMANCE ANALYSIS
}

\author{
DOI: 10.17261/Pressacademia.2018.907 \\ PAP- V.7-2018(60)-p.321-325
}

\section{Husniye Ors ${ }^{1}$, Ahmed Yusuf Sarihan ${ }^{2}$}

${ }^{1}$ Gazi University, iktisadi ve Idari Bilimler Fakültesi, Ankara, Turkey.

ohusniye@gmail.com, ORCID: 0000-0002-8319-3340

${ }^{2}$ Bandirma Onyedi Eylul University, Ö.S. Uygulamalı Bilimler Fakültesi, Balikesir, Turkey.

asarihan@bandirma.edu.tr, ORCID: 0000-0001-7119-9852

To cite this document

Ors, H., Sarihan, A. Y. (2018). The importance of free zones on Turkey's export: preliminary research within the framework of purposeperformance analysis. PressAcademia Procedia (PAP), V.7, p.321-325.

Permemant link to this document: $h$ ttp://doi.org/10.17261/Pressacademia.2018.907

Copyright: Published by PressAcademia and limited licenced re-use rights only.

\section{ABSTRACT}

Purpose- Export has a crucial importance for emerging economies. Increasing export is equated with increasing wealth of people and economic power. In this context developing countries such as Turkey engages some export promotion policies in order to encourage entrepreneurs to export. These promotion policies can be in the form of direct investment and export incentives, as well as enacting laws on free zones. Free zones in Turkey is run by the Free Zones Act No. 3218. According to this law, the free zones should encourage the investment and production to direct exports, to attract foreign dricet investment and technology to the country, to direct businesses in country to export and to improve international trade. The purpose of this study is to emphasize on the importance of free zones in Turkey's export and to determine what are the purposes of free zones and how far have they been achieved, with managers perspective. Methodology- In-depth interviews have been conducted with free zones' managers.

Findings- This study had proved that free zones are successful to increase export, attract foreign investors and provide technology input. Conclusion- For the future researchers, quantitative research on the free zones' performance analysis by using the current data from primary research is recommended.

Keywords: Free zone, export, purpose-performance analysis, in-depth interview.

JEL Codes: F13, F15, F18

\section{SERBEST BÖLGELERIN TÜRKIYE'NIN IHRACATINDAKI ÖNEMI: AMAÇ-PERFORMANS ANALIZi ÇERÇEVESINDE ÖN ARAŞTIRMA}

ÖZET

Amaç- Gelişmekte olan ekonomiler için ihracatın önemi büyüktür. İhracatı artırmak ülkeler için halkın refahını ve ekonomik gücü artırmakla denk görülmektedir. Bu bağlamda Türkiye gibi gelişmekte olan ülkeler girişimcilerini ihracata kazandırmak için türlü teşvik politikaları yürütmektedir. Bu teşvik politikaları doğrudan yatırım ve ihracat teşvikleri şeklinde olabildiği gibi serbest bölgeler hakkında kanunlar çıkartmak şeklinde de olabilir. Türkiye'de serbest bölgeler 3218 sayılı Serbest Bölgeler Kanuna göre işletilmektedir. Bu kanuna göre serbest bölgelerin amacı yatııımları ve üretimi ihracata yöneltecek şekilde teşvik etmek, doğrudan yabancı yatırım ve teknolojiyi ülkeye çekmek, ülkedeki işletmeleri ihracata yöneltmek ve uluslararası ticareti geliştirmektir. Bu çalışmanın amacı serbest bölgelerin Türkiye'nin inracatındaki önemine değinerek bu bölgelerin amaçlarının neler olduğu ve performanslarının bu amaçlara ne kadar yaklaştığııı serbest bölge yöneticileri bakış açııı ile ortaya çıkartmaktır.

Yöntem- Serbest bölgelerin yöneticileri ile derinlemesine mülakat yapılmıștır.

Bulgular- Araştırma ile serbest bölgelerin ihracatı artırma, yabancı yatırım çekme ve teknoloji girişi sağlamada başarılı oldukları ortaya konmuştur.

Sonuç- Gelecekteki araştıııılar için mevcut birincil araştırma ile elde edilen bulgular kullanılarak serbest bölgelerin performans analizi konulu nicel araştırmalar yapmaları önerilir.

Anahtar Kelimeler: Serbest bölge, ihracat, amaç-performans analizi, derinlemesine mülakat.

JEL Kodları: F13, F15, F18 


\section{GíRiş}

Literatürde gelişmekte olan ülkelerde ihracatın artırılması ile iktisadi büyüme arasındaki ilişkiyi inceleyen sınırsız çalışmalar görmek mümkündür. Bu çalışmalara göre ihracat gelişmekte olan ülkelerin ilerleme süreçleri için kritik bir rol üstlenmiştir (Chenery ve Strout, 1966; Kessing, 1967; Velasco, 1988; Balassa, 1989). Balassa'ya (1989) göre ihracatı artırıcı politika izleyen az gelişmiş ülkeler ithal ikameci politika izleyenlere göre çok daha hızlı gelişim göstermektedir. Örnek vermek gerekirse; uzak doğu ülkelerinin endüstrileşmesi ve sürekli ihracat odaklı tutumlarının ekonomik büyüme ile sonuçlanması gösterilebilir. (Rutashobya, 2003: 226). Chow (1987) yaptığı çalışmada ihracatın artması ile endüstrileşme arasında nedensellik ilişkisi olduğunu bulmuştur. Bu anlamda Türkiye gibi gelişmekte olan ülkeler için de planlı endüstrileşme ile ihracata yönelik yatırımların sağlayabileceği katkıları anlamak zor olmayacaktır.

Gelişmekte olan ülkeler sınıfında bulunan Türkiye'de yıllardır süregelen dış ticaret açığı gözlemlenmektedir (TÜik, 2017). İthalatın, ihracattan fazla olması ve ihraç edilen ürünlerin yurt dışında ikamesinin rahatlıkla başka ülkelerden de sağlanabiliyor olması Türkiye için büyük bir sorundur. Dahası ihraç edilen ürünlerin hammaddelerinin ithalat ile sağlanmaktadır. Bu anlamda Türkiye için doğrudan kendi kaynakları ile katma değerli ürünler üretmek ve dünya piyasalarında bu ürünlerin rekabetini sağlamak büyük önem arz etmektedir. Dolayısıyla hükümetlerin, iş çevrelerinin ve araştırmacıların dikkati ihracatı artırmak üzerinde yoğunlaşmaktadır. ỉhracatı artırmak konusunda önemli konulardan bir tanesi de serbest bölgelerin ihracatta oynadıkları roldür. Dikili (2011: 53) serbest bölgelerin rolünü firmaların maliyetlerini düşürmek ve uluslararası pazarlarda rekabet edebilir konuma gelmeleri için katkıda bulunmak olarak mikro anlamda özetlerken; makro anlamda ülkelerin ekonomik kalkınmasında büyük önem arz ettiğine değinmiştir.

Serbest bölgelerin gelişmekte olan ülkeler için ihracat ve ekonomik büyüme odaklı kalkınma yolunda önemli bir dönüm noktası olduğu söylenebilir. Johansson ve Nilsson, (1997) serbest bölgeler gibi ticareti teşvik edici çevrelerin oluşturulmasının doğrudan yabancı yatırımları çekme potansiyelinin yüksek olduğunu ve yerel ürünlerin ihracatını artırmada anahtar sorumluluk üstlendiğini açıklamıştır. Bu gibi çalışmaların asıl vurgulamak istedikleri, serbest bölgelerin gelişmekte olan ülkelerdeki bilgi, tecrübe ve teknoloji eksiklerini gidermede teşvik edici rolü ile rekabet gücüne ön ayak olma özellikleridir. Bu özellikleri ile serbest bölgelerin ülke ekonomisine potansiyel katkıları görülmekle beraber tam fonksiyon işlemeleri halinde bu potansiyele ulaşılmasının oldukça mümkün olduğu anlaşılmaktadır. Bu bağlamda serbest bölgelerin kendileri için önceden belirlenen amaçlara ne kadar hizmet ettiği önem kazanmaktadır.

Amaçların başarıları yani belirlenen amaçlara ne oranda ulaşıldığı meselesi, performans ile ilişkilendirilmektedir. Bir birey, işletme, devlet kurumu veya bizzat devlet, amaçlarını başarı ile tamamladığı zaman kendini yüksek performans sahibi olarak görebilir. Kubalı (1999: 32) performansı, amaçlı ve planlı operasyonlar neticesinde elde edileni nicel ve nitel olarak belirleyen bir kavram olarak tanımlamıştır. İşletmeler için hedeflenen amaçlar doğrultusunda elde edilen çıktılar yani verimlilik, etkinlik, etkililik, karlılık ve kalite gibi kavramlar performans ölçütü olarak tanımlanabilmektedir (Karaman, 2009: 413). Öyleyse, gelişmekte olan ülkeler için önemi daha önce vurgulanan serbest bölgelerin performansları da, devletin teşvikleri vermesinin altında yatan amaçlara ne kadar başarılı şekilde ulaşıldığı ile bağdaştırılacaktır. Buradan hareketle bu çalışmanın yapılmasında karar kılınmıştır.

\section{LITERATÜR TARAMASI}

Küreselleşme ile artan ticari entegrasyonların sermaye, iş gücü, teknoloji, bilgi, mal ve hizmet dolaşımını dünya geneline yaydığı bilinen ve yaşanan bir gerçektir. Küreselleşme ile ürünlerin dünya çapında yayılması ile rekabette uluslararası arenaya taşınmıştır. Rekabetin en üst düzeyi olan bu nokta da ülkeler işletmelerinin ve endüstrilerinin rekabet edebilirliği kadar güçlüdür (Öztürkler, 2010). Bu bağlamda işletmeleri uluslararası ticarete, özellikle ihracata teşvik edici politikalar geliştirilmektedir. Bunun sebebi işletmelerin yapacağı ihracatın ülkeye döviz kazandıracak olması ve küreselleşmenin bir parçası olan ithalattan doğan borçların ödenmesini kolaylaştıracak olmasıdır. Böylece ekonomik kalkınma ile beraber halkın refahında da artış meydana gelecek ve oluşan olumlu ekonomik göstergeler ülkenin uluslararası rekabette daha güvenli bir liman olarak görülmesini sağlayarak döngüsel bir süreç başlatacaktır. Bu bağlamda yürütülen politikalardan biriside serbest bölgeler kurulmasıdır.

Serbest bölgeler bir ülkenin siyasal sınırları içinde bulunan ancak özellikle gümrük uygulamaları başta olmak üzere çeşitli ticaret politikası önlemlerinde kısıtların dışında tutulan alanlar olarak tanımlanabilir (Öztürk, 2013: 76). Gümüş (2007: 48) benzer bir tanımla ülkenin egemenlik sınırları içinde bulunup o ülkenin gümrük sınırları dışında yer alan alanlar olarak açıklama getirmiştir. Literatürde yapılan tanımlamaların genelde "bölge” kavramı üzerinde yoğunlaştığı görülmektedir. Bunun bir örneği de Tümenbatur'un (2012: 339) yaptığı tanımda görülen; gümrük sınırları dışında tutulan özel bölgeler açıklamasıdır. Bu tanımların eksik noktası serbest bölgelerin tam olarak amaçlarını ve özelliklerini içermemeleridir. Bu anlamda 3218 Sayılı Serbest Bölgeler Kanunu'ndan en iyi açıklamalar elde edilebilir. İlgili kanununa göre serbest bölgeler:

“ihracata yönelik yatırım ve üretimi teşvik etmek, doğrudan yabancı yatırımları ve teknoloji girişini hızlandırmak, işletmeleri ihracata yönlendirmek ve uluslararası ticareti geliştirmek amacıyla kurulan bölgelerdir."

Bu bilgiler ışığında serbest bölgelerin en genel tanımı "fiilen ülke sınırları içerisinde bulunan topraklar üzerinde, ihracat odaklı yatırım ve üretimi desteklemek, doğrudan yabancı yatırımlar ile teknoloji ve teknik bilgi girişini hızlandırmak, işletmelerin ihracata katılımını sağlamak ve ülkenin küresel rekabet gücünü artırmak amacıyla kurulan ancak çeşitli vergi istisnaları ve ekonomik destekler açısından ülke sınırları dışarında kabul edilen bölgeler" şeklinde yapılabilir. Böylelikle serbest bölgeler hakkında en geniş anlamda fikir sahibi olunacak bir açıklama sağlanmış olacaktır. Önceki tanımların bu kadar kapsamlı olmaması belki de serbest bölgeler konusunda yeterince çalışma yapılmaması ile ilgilidir. Nitekim Dikili (2011: 53) serbest bölgelerin gerek Türk gerekse dünya literatüründe yeterince incelenmeyen bir konu olduğuna dikkat çekmiştir.

Öztürk (2013) yılında yaptığı çalışmada küreselleşmenin etkilerini dikkate alarak dünya ve Türkiye'deki serbest bölgelerin geleceğini incelemiştir. Çalışmada serbest bölgelerin tarihsel geçmişinden başlayarak günümüzde aldıkları son şekilleri yorumlanmıştır. Çalışma sonucunda serbest bölgelerin vaat ettiği avantajların küreselleşmenin getirileri ile beraber anlamsız hale geleceği ve serbest bölgelere ihtiyaç duyulmayacağı öngörülmüştür. Bu durumun Türkiye'nin ekonomik entegrasyonunun artması ile beraber ülke içindeki serbest 
bölgeler içinde geçerli olacağı tahmin edilmiştir. Bu bağlamda literatürde serbest bölgelerin avantajları olarak sayılan özellikleri şu şekilde sınıflandırılmıştır:

- Serbest bölgede üretilecek mal ve hizmetler için vergi avantajlarından yararlanma imkanı (Dikili, 2011; Öztürk, 2013; Gümüş, 2007; Öztürk vd., 2009; Tümenbatur, 2012; Bakan ve Gökmen, 2014; Hava, 1999; Taşoğlu, 2012; Sarvan vd., 2010; Orhan, 2003; Arslan ve Yapraklı, 2007; Demirel, 2009)

- Süreleri önceden belirli olan faaliyet ruhsatları sayesinde işletmeler için geleceği planlayabilme ve ürünlerin serbest bölge içinde sınırsız tutulabilme imkanı (Dikili, 2011; Tümenbatur, 2012; Bakan ve Gökmen, 2014, Sarvan vd., 2010)

- Kazanılan gelirlerin izne tabi olmadan yurt dışına veya ülke içinde transferi imkanı (Dikili, 2011; Öztürk, 2013; Tümenbatur, 2012; Orhan, 2003)

- Kanunlar açısından ülke sınırları dışında tutulan bir bölge olma özelliğinin beraberinde getirdiği ticaret politikası önlemlerine tabi tutulmamadan kaynaklı kolaylıklar (Dikili, 2011; Öztürk, 2013; Hava, 1999)

$\mathrm{Bu}$ avantajlara ek olarak serbest bölgelerin kurulduğu alanların genelde uluslararası taşımacılık faaliyetlerinin gerçekleştirilmesi açısından avantajları konumlandırıldığı bilinmektedir. Tüm bu avantajlar ve kanunda belirtilen amaçlardan da görüldüğü üzere serbest bölgeler işletmeler için büyük fırsatlar sunmakta ve bu fırsatların karşılı̆̆ını ülkeye sağlanması beklenen makroekonomik faydalardan beklemektedir. Tümenbatur (2012) serbest bölgelerin Türkiye ekonomisine katkılarını incelediği araştırmasında, bölgelerin bazı dönemlerde Türkiye ihracatının \%20'sine varan katkılar sağladığını aktarmıştır. Bir başka araştırmada Karaduman ve Yıldız (2002) yılında Türkiye'nin ihracatının \%12'sinin serbest bölgelerden sağlandığını ve ekonomiye olumlu katkıları olduğunu tespit etmişlerdir. Rutashobya (2003) ihracat odaklı serbest ticaret bölgelerin ülke ekonomisine doğrudan katkıları olduğunu ifade etmiştir. Hava (1999) Ege Serbest Bölgesinin ekonomiye etkisini göstermek amacıyla bölgedeki yatııımı \%96,4'ünün yabancı sermayeden geldiğini, ticaret hacminin o dönem için 1 milyar dolar olduğunu ve 3550 kişiye istihdam sağladığını ortaya koymuştur. Bu bilgilere göre literatürden anlaşıldığı kadarıyla serbest bölgelerin kendilerinden beklenen faydaları sağladığı görülmektedir.

Serbest bölgelerin makroekonomik olarak doğrudan sağladığı faydaların yanında konumlandırıldığı çevreye getireceği dolaylı ekonomik faydalarda söz konusudur. Serbest bölgelerin bulunduğu illere yönelik ekonomik etkilerinin araştırıldığı bir çalışma da serbest bölge bulunan illerin kullandığı krediler ve ekonomik büyüme anlamında yapılan analizler sonucunda anlamlı ve pozitif olarak diğer illerden farklılık gösterdiği bulunmuştur (Öztürk vd, 2009). Benzer anlamda bir çalışmada Taşoğlu (2012) liman ve serbest bölgenin şehir için cazibe bağlamında reklamı yapılması gereken ekonomik değerler olduğunu vurgulamışlardır. Orhan (2003) serbest bölgelerin kurulduğu coğrafyaya ekonomiyi canlandırıcı katkıları olduğunu aktarmıştır.

Bakan ve Gökmen (2014) serbest bölgeler ve dış ticaret ilişkisini analiz ettikleri çalışmalarında Gaziantep Serbest Bölgesini örnek olarak almışlardır. Bu çalışma sonucunda serbest bölgelerden yapılan çeşitli kısıtlamalardan arındırılmış olması sebebiyle ülkelerin dış ticaret hacmine olumlu katkı sağlayabilecek potansiyelinin var olduğu yorumu getirilmiştir. Arslan ve Yapraklı (2007) yine Gaziantep'te yapılan çalışmalarında serbest bölge çalışanlarından anket yoluyla toplanan veriler üzerinde yaptıkları analizler sonucunda serbest bölge çalışanlarının, bölgenin şehir ekonomisine katkılarını ortaya koymuşlardır. Buna göre serbest bölgeden araştırmaya katılan 87 kişiden 79 'u çalıştıkları serbest bölgenin bulundukları şehre yeterli düzeyde ekonomik etkileri olduğunu söylemişlerdir. Ayrıca çalışanların büyük çoğunluğunun (\%80) serbest bölgenin varlığının şehrin ekonomik düzenine canlılık getirdiğine inandığı görülmektedir.

Literatürden ve ilgili kanundan hareketle serbest bölgelerin amaçları ve potansiyel avantajları ortaya konulmuştur. Bu bilgiler ışı̆̆ında özetlemek gerekirse serberst bölgelerin öncelikle ihracatı artırma, yabancı yatırım çekme ve teknoloji girişi sağlama gibi kriterlere odaklanması gerektiğine inanılmaktadır.

Bu kriterlerin önerilmesi sürecinde Karaman’ın (2009) aktardığı boyutlardan yola çıkılarak serbest bölgeler açısından yorum getirilmiştir. Bu performansların ölçümü Akal'ın (2000) aktardığı "ölçülen yapılmıştır" ve "ölçemediğinizi yönetemezsiniz" deyişlerinden çıkartılacak anlamlar açısından önemlidir. Yenice (2006: 57) performans ölçümünü kullanılan kaynakların elde edilen sonuçlar ile takip edilmesi olarak özetlemiştir. Serbest bölgeler için kullanılan kaynak kavramını direkt olarak ele almak mümkün olmasa da belirlenen amaçlar ile elde edilen sonuçların karşılaştırması ile performans analizi mümkün olacaktır.

\section{3. ÜLKE IHRACATI VE SERBEST BÖLGELER}

Bu çalışmada asıl dikkat çekilmek istenen noktalardan bir diğeri Türkiye'den ihraç edilen ürünlerin ne kadarının Türkiye'deki serbest bölgelere yapıldığı ve bu ağırlığın nasıl anlamlandırılabileceği üzerinedir. Yani fiili olarak ülke sınırları dışına çıkmayan ihraç mallarının siyasal olarak ülke sınırları dışına gitmesi ve bunun ülke ihracatında gösterilmesi hususudur. TÜik (2017) istatistiklerine göre bu rakamlar 2007 yılından 2016 yılının sonuna kadar 3 milyar \$ düzeylerinden 1,8 milyar \$ düzeyine düşmüştür. Yüzde olarak oranlarına bakıldığında \%2,7 düzeyinden $\% 1,3$ düzeyine gerileme şeklinde görülmektedir. Burada önemli olan serbest bölgelere yapılan ihracatın azalması değil, ülke ihracatı içerisinde serbest bölgelere yapılan ihracatın gerçek anlamda ihracat olarak adlandırılıp ekonomik kalkınmaya katkı olarak gösterilmesidir. Gelişmekte olan ülkelerden birisi olarak sınıflandırılan Türkiye için toplam ihracat içindeki payın \%1,8 ile \%3 arasında gidip gelmesi ihracatın bir kısmının tam anlamıyla ihracat olarak adlandırılamayacağı gerçeğini göstermektedir. Bahsi geçen değerler düşük miktarlar olmamakla beraber ülke ekonomisi için muhtemel etkileri sadece ihracat gösterilen rakam olarak kalmayacaktır. Çalışmanın önceki kısımlarında belirtilen vergi muafiyetlerinden bazıları şunlardır:

- Serbest bölgeye yapılan ihracatta ihracatçı firmalar KDV iadesi alabilirler.

- Serbest bölgenin Türkiye'den yaptığı ithalatta ticaret politikası önlemlerine tabi olmaksızın ithalat vergileri de tahsil edilmez. 
Bu durumda normal koşullarda ülke dışından ithal edilecek bir malın ülkeye girişinde doğacak gümrük vergileri kaybolmuş olacağı gibi gerçek anlamda ülke sınırlarını terk etmeyen mallar içinde KDV kaybı oluşacaktır. Bu açıdan kayıpların önlenmesi için serbest bölgelerin içerisinden yurt dışına ihracatın sürdürülebilir olması önemlidir. Ekonomi Bakanlığı (2017) verilerine göre açıklanan istatistikler en son 2015 yılı için verilmiştir. Bu veriler ışığında serbest bölgelerden yurt dışına yapılan ihracat 2015 yılı için 7,5 milyar dolar olarak dikkat çekmektedir. Ekonomi Bakanlığının güncel verileri yayınlamamış olması bir eksiklik olarak dikkat çekmektedir. Fakat 2015 yılı için bakıldığında Türkiye'den serbest bölgelere yapılan ihracat 2,2 milyar dolar iken serbest bölgelerden yurt dışına yapılan ihracatın 7,5 milyar dolar olması yukarıda bahsedilen olumsuzlukların gerçekleşmemesi anlamına geliyor olabilir.

Ekonomi Bakanlığı (2017) verilerine göre Türkiye'de faaliyet gösteren 19 serbest bölge vardır. Bu bölgelerin 2015 yılı toplam ticaret hacmi 22,4 milyar dolar olarak gerçekleşmiştir. Serbest bölgeler Türkiye'den mal alıp Türkiye'ye mal sattığı gibi dünyanın çeşitli bölgeleri ile de ticaret halindedir. Ekonomi Bakanlığı (2017) verilerine göre OECD ülkeleri ile ticaret hacmi 8,7 milyar dolar olarak gerçekleşen Türkiye serbest bölgeleri Avrupa, Kuzey Afrika ve Ortadoğu ile sürekli ticari ilişkiler yürütmektedir.

Ticari ilişkilerinin yanı sıra serbest bölgeler sağladığı istihdam ile de dikkat çekmektedir. Türkiye serbest bölgelerinde 2015 yılında toplam 61.505 kişinin çalıştığı görülmektedir. Bu rakamın \%25'inden fazlasına Ege Serbest Bölgesinin ev sahipliği yaptığı dikkat çekmektedir. Ege Serbest Bölgesini sırasıyla Mersin, Bursa ve Antalya takip etmektedir. Ticareti yapılan ürünlerin sektörel hacimlerine bakıldığında ise $\% 90$ ’ının sanayi ürünlerinden oluştuğu görülmektedir.

\section{YÖNTEM}

Çalışma sürecinde serbest bölgelerden gerçekçi ve derinlemesine bilgiler almak, bölge yöneticilerinin konulara ilişkin algılarını anlamak amacıyla nitel araştırma yöntemlerinden derinlemesine mülakat yöntemi kullanılmıştır. Türkiye'deki toplam 15 Serbest Bölgeye tam sayım uygulanmış ve üst düzey yöneticilerine görüşme talebi gönderilmiştir. 15 Serbest Bölge yöneticisinden beş tanesi olumlu cevap vermiş olup, araştırma beş Serbest Bölge üst düzey yöneticileri ile gerçekleşmiştir.

Yöneticilere sorulan sorular çalışmanın literatür kısmında incelenen konulardan hareketle; ihracat performansı, yatırım çekme performansı, teknoloji sağlama performansı ve diğer amaçlara göre performanslar şeklinde sınıflandırılmıştır. Derinlemesine mülakatlar sonucu elde edilen bulgular araştırmanın sonuç ve tartışma başlığı altında açıklanmış ve değerlendirilmiştir.

\section{SONUÇ VE TARTIŞMA}

Derinlemesine mülakatlar sonucunda serbest bölge yöneticilerinin, ihracatı artırma amacına yüksek performans ile ulaşıldığına dair kanaatleri olduğu görülmektedir. Yöneticilerin bu amaca ulaşılmasının arkasında kurumsallaşmayı, doğru firmaların serbest bölgelerde yer almasını, mevzuatları, yabancı yatırımcıları ve bölge genişletme çalışmalarını gördüğü dikkat çekmektedir. Ayrıca yöneticilerin serbest bölgeleri ihracat amacından alıkoyma ihtimali olan konular olarak jeopolitik sıkıntıları, ekonomik istikrarsızlıkları, bürokratik sorunları, yetersiz tanıtımları ve ekonomik krizleri ele aldıkları sonucu ortaya konulmuştur. Serbest bölge yöneticileri ihracatı artırmak için, serbest bölgelerdeki hizmetlerin artırılması, bölgelerin pazarlama ve tanıtım faaliyetleri yürütmesi, mevzuatların daha uygulanabilir hale getirilmesi, teşviklerin artırılması ve sürekli iyileştirmenin uygulanması gibi gerekliliklerin olmasına vurgu yaptıkları görülmektedir.

Mülakatlar sürecinde incelenen bir diğer konu olan serbest bölgelerin ülkeye yabancı yatırım çekme amacı konusunda yöneticilerin kanaatleri incelendiğinde, bölgelerin yabancı yatırımcıları çekme konusunda çok büyük problemlerle karşılaşmadıkları aktarılmıştır. Ayrıca bölgelere yatırım yapanların karşılığını aldığına dair genel bir kanı olduğu görülmektedir. Serbest bölgelerin yeterince yabancı sermaye çekmesinin önünde bazı engeller olduğu vurgulanmıştır. Bu engellerin neler olduğu sorulduğunda alınan yanıtlar yetersiz tanıtımlar, bürokratik işlerdeki yoğunluk ve yabancılara sağlanan faydalardaki istikrarsızlıklar şeklinde sıralanmıştır. Yabancı yatırım çekme başarısının arkasında ise kaliteli hizmetler, etkin pazarlama, yardımsever ve iş bilen bölge yönetimleri, reklamlar ve coğrafi konum gibi etkenler gösterilmiştir.

Teknoloji sağlama amacına yönelik performans ile ilgili mülakatlardan elde edilen sonuçlara bakıldığında serbest bölgelerin, teknolojiyi kullanma hususunda herhangi bir problem olmadığı görülmektedir. Ülkeye teknoloji girişinin artırılması için bölgelerde katma değerli ürünler üreten firmalara yer verilmesi gerektiği, yabancı sermayeli firmaların artırılması gerektiği ve nitelikli ürünler için alt yapının sağlanması gerektiği vurgulanmıştır. Teknoloji girşini etkileyen unsurlar olarak; nitelikli iş gücü durumunu, yabancı sermaye oranını, girişimci karakteristiklerini ve ar-ge desteklerini gösteren yöneticiler, teknoloji girişi sayesinde katma değeri yüksek ürünler üretildiğini, know-how transferi sağlandığını, kalitenin arttığını, karlılığın arttığını ve verimlilik ile ihracatı tetiklediğini vurgulamışlardır.

Serbest bölgelere dair diğer amaçlar hakkında sorulan sorulardan alınan yanıtlar neticesinde ise bölgelerin sosyal imkanlarının iyi fakat geliştirilebilir olduğu, coğrafi konumlarının ve lojistik imkanlarının verimli olduğu, ülke ekonomisine istihdam bağlamında katkı sağlandığı ve personellere yönelik özlük haklarını iyileştirme amacının olduğu vurgulanmıştır.

Elde edilen bulgular, serbest bölgelerin amaçları ile bu amaçlara ulaşma performansları bağlamında tanımlayıcı bilgiler niteliğindedir. Elbette nitel araştırmaların doğası gereği, kesin araştırmalar gibi ıspatlanmış teorileri içermeyen bu bulgulardan hareketle geliştirilecek hipotezlerin gelecekteki çalışmalarda test edilmesi önerilir. Mevcut çalışma, gelecekteki çalışmalar için bir ön araştırma niteliğini taşıdığından sonraki araştırmaların nicel araştırmalarla ilerlemesi önerilmektedir. 


\section{KAYNAKLAR}

Akal, Z. (2000). İşletmelerde performans ölçüm ve denetimi, çok yönlü performans göstergeleri. Ankara: Milli Prodüktivite Merkezi Yayınları, No:473.

Arslan, İ., Yapraklı, S. (2007). Serbest bölgelerin ekonomik etkileri: Gaziantep Serbest Bölgesi'nin etkilerine ilişkin bir saha araştirması. Gaziantep Üniversitesi Sosyal Bilimler Dergisi, 6(2), 168-179.

Bakan, S., Gökmen, S. (2014). Serbest bölgeler ve dis ticaret iliskisi: Gaziantep Serbest Bölgesi örneği. Elektronik Sosyal Bilimler Dergisi, 13(51), 34-51.

Balassa, B. (1989). Inward-looking import substitution. Industrial adjustment in Sub-Saharan Africa. New York: Oxford University Press/The World Bank, 36-38.

Chenery, H. B. (1967). Foreign assistance and economic development. In Capital Movements and Economic Development (pp. 268-292). Palgrave Macmillan, London.

Chow, P. C. (1987). Causality between export growth and industrial development: empirial evidence from the NICs. Journal of development Economics, 26(1), 55-63.

Demirel, G. (2009). Türkiye'de serbest bölgeler ve Ab uygulamalari.

Dikili, A. (2011). Türkiye serbest bölgeleri. Ortadoğu Analiz, 3(25), 52-59.

Ekonomi Bakanlığı, (2017). Serbest Bölge Erişim Istatistikleri, https://www.ekonomi.gov.tr/portal/faces/home/yatirim/serbestBolgeler;j, Erişim Tarihi: 11.11.2017

Gümüş, E. (2007). Serbest bölgelerde vergi uygulamalarinin değerlendirilmesi. Atatürk Üniversitesi İktisadi ve İdari Bilimler Dergisi, 21(1), 47-60.

Hava, H. T. (1999). Serbest bölgeler ve Ege Serbest Bölgesi: bir durum değerlendirmesi. Dokuz Eylül Üniversitesi İktisadi ve İdari Bilimler Fakültesi Dergisi, 14(1), 113-124.

Hava, H. T. (2009). Serbest bölgeler ve Ege Serbest Bölgesi: bir durum değerlendirmesi.

Johansson, H., Nilsson, L. (1997). Export processing zones as catalysts. World Development, 25(12), 2115-2128.

Karaduman, N., Yıldız, A. G. Z. (2002). Serbest bölge uygulamalarinin diş ticarete ve yabanci sermayeye katkilari. Süleyman Demirel Üniversitesi İktisadi ve İdari Bilimler Fakültesi Dergisi, 7(1), 133-152.

Karaman, R. (2009). İşletmelerde performans ölçümünün önemi ve modern bir performans ölçme araci olarak Balanced Scorecard. Sosyal Ekonomik Araştırmalar Dergisi, 8(16), 410-427.

Keesing, D. B. (1967). Outward-looking policies and economic development. The Economic Journal, 303-320.

Kinunda-Rutashobya, L. (2003). Exploring the potentialities of export processing free zones (EPZs) for economic development in Africa: lessons from Mauritius. Management Decision, 41(3), 226-232.

Kubalı, D. (1999). Performans denetimi. Amme İdaresi Dergisi, 32(1), 31-62.

Orhan, A. (2003). Serbest bölgelerin sağladiği avantajlar: KOSBAŞ örneği. Kocaeli Üniversitesi Sosyal Bilimler Ensitütüsü Dergisi, 6(1), 117131.

Öztürk, L. (2013). Serbest bölgelerin geleceği: Türkiye açisindan bir değerlendirme. Uluslararası Yönetim İktisat ve İşletme Dergisi, 9(19), 7586

Özturk, L., Değer, M. K., Değer, S. (2009). Kentsel ekonomik büyümede serbest bölgeler: politik veya ekonomik tercih mi?. Ataturk University Journal of Economics \& Administrative Sciences, 23(1).

Öztürkler, H. (2010). Türkiye, Suriye, Ürdün Ve Lübnan serbest ticaret bölgesi Türkiye için Avrupa Birligine bir alternatif oluşturabilir mi?. Middle Eastern Analysis/Ortadogu Analiz, 2(23), 51-57.

Sarvan, F., Durmuş, E., Yenidoğan, T. G., Dirlik, O. (2010). Antalya Serbest Bölgesi'nde yat üretim kümesinin gelişimi: kaynaklara dayali bir analiz. Akdeniz Üniversitesi İktisadi Ve İdari Bilimler Fakültesi Dergisi, (19), 286-312.

Taşoğlu, P. N. (2012). Mersin'in marka kent olma sürecinde liman ve serbest bölgeye ilişkin internet pazarlamasi uygulamalarinin rolü. AJITE: Online Academic Journal of Information Technology, 3(6), 67-76.

TÜiK, (2017). Dış ticaret istatistikleri. Erişim Linki: https://biruni.tuik.gov.tr/disticaretapp/menu.zul, Erişim Tarihi: 11.11.2017.

Tümenbatur, A. (2012). Serbest bölgeler ve Türkiye ekonomisine katkilari üzerine bir değerlendirme. Çukurova Üniversitesi Sosyal Bilimler Enstitüsü Dergisi, 21(3), 339-356.

Yenice, E. (2006). Kamu kesiminde performans değerlendirmesi. Maliye Dergisi, 150, 122-132. 